\section{Decline of melanic moths}

SIR - Industrial melanism has been best documented in Biston betularia, the peppered moth. Melanic variants, unknown before 1848, all but replaced paler forms by the turn of the century in populations near British industrial centres. Distant rural populations, however, changed little $^{1}$. The changes have been attributed to habitat modifications and differential predation on the moths by birds ${ }^{1}$.

Conditions began to reverse following the creation of smokeless zones in the United Kingdom initiated by the Clean Air Act of 1956. Beginning in 1959 the Biston population at Caldy common, 18 $\mathrm{km}$ west of Liverpool, has been sampled each year ${ }^{2}$. There the frequency of the melanic form has dropped from a high of $94.2 \%$ in 1960 to its current (1994) low of $18.7 \%$ (65 melanic of 348 ). Similar reversals are well documented elsewhere in Britain, but the Caldy Common sample is by far the largest, with nearly 18,000 specimens taken to date.

Melanism has also been reported in the American subspecies of the peppered moth, $B$. betularia cognataria. Melanics have remained at low frequencies in rural Massachusetts between 1958 and 1977 (ref. 3), and in the Virginia mountains (1968-94, D. A. West, personal communication); whereas in central Pennsylvania melanics were once appreciably high in frequency and fell from 52 to $38 \%$ between 1971 and 1986 (ref. 4). The only North American location where melanic Biston has been recorded at frequencies comparable to British samples (exceeding $90 \%$ ) is in southern Michigan ${ }^{5}$. Between 1959 and 1961, a combined total of 576 Biston have been collected at the E. S. George Reserve, a rural field station near Detroit. The sample sizes ranged from 24 to 173 over five generations (in Michigan the species is bivoltine), with no statistical difference in the distributions of melanics to non-melanics $\left(G_{4}=1.433, P>0.75\right)$. In all, 515 of the 576 were melanic ${ }^{5}$.

To determine if the frequency of melanic Biston has changed since the last census was taken at that location more than 30 years ago, we ran moth traps there for 7 weeks during last summer. Because of comparable sample sizes and the sample intervals, the most appropriate comparison is between the last sample taken (second brood, 1961) and the current sample. That 1961 sample, with 22 melanics and 2 non-melanics $(n=24)$, and the 1994 sample of 4 melanics and 21 nonmelanics $(n=25)$, differ very significantly $\left(G_{1}=31.99, P<<0.001\right)$.

The 1994 Michigan and the 1994 Liverpool samples do not differ in the frequency of melanics $\left(G_{1}=0.115, P>0.5\right)$. Although there are no intermediate sample points from the George Reserve, the nearly matching drop in the frequency of melanics from above $90 \%$ to below $20 \%$ at these two locations over the same 35-year time interval is either an extraordinary coincidence, or parallel evolution.

A "parallel" Clean Air Act in 1963, with subsequent amendments, also led to reductions in atmospheric pollution in the United States ${ }^{6}$. Despite general improvements in most indicators of air quality, southeastern Michigan falls within the acid-rain belt ${ }^{6}$. However, the George Reserve was not conspicuously blackened before clean. air legislation, nor has the habitat changed in this regard since then (D.F.O., unpublished data). It has remained a woodland habitat of mixed deciduous trees, many of them darkbarked oaks (Quercus spp.) and black walnuts (Juglans nigra). Furthermore, there has been no perceptible change in the lichen flora in that region of Michigan over the past 30 years $(\mathrm{H}$. Crum, personal communication); thus, it appears that the rise and subsequent fall in melanism in the Biston population on the George

Reserve is not related to lichen succession. Although the evolution of melanism in this southern Michigan population seems to have paralleled the changes in British populations in both directions, common causes for the changes are not obvious. Clearly, more extensive sampling of American Biston is needed.

\title{
Bruce Grant
}

Department of Biology,

College of William and Mary,

Williamsburg, Virginia 23187, USA

Denis F. Owen

School of Biological and

Molecular Sciences,

Oxford Brookes University,

Oxford OXЗ OBP, UK

Cyrll A. Clarke

Department of Genetics

and Microbiology,

University of Liverpool,

Liverpool L69 3BX, UK

\footnotetext{
1. Kettlewell, B. The Evolution of Melanism (Clarendon, Oxford, 1973)

2. Clarke, C. A., Grant, B., Clarke, F. M. M. \& Asami, T.

The Linnean 10, 18-26 (1994).

3. Treat, A. E. J. Lepid. Soc. 33, 148-149 (1979).

4. Manley, T. R. J. Lepid. Soc. 42, 213-217 (1988).

5. Owen, D.F. Ann, ent. Soc. 55, 695-703 (1962).

6. Anderson, S. H. et al. Environmental Science, 4th edn. (Macmillan, New York, 1993).
}

\section{Hydrophobicity and phylogeny}

SIR - Mitochondrial DNA (mtDNA) sequences are routinely used to infer the pattern and timing of evolutionary divergences ${ }^{1}$. Various methods for estimating phylogenies are used, each based on a different model of evolution. All these methods assume some model of evolutionary change, whether explicitly, as is the case for the likelihood procedures, or impli-citly, as is the case for other methods $^{2,3}$. A lack of correspondence between an underlying model and actual evolutionary processes can lead to failure of a method. Unfortunately, several of the underlying models fail to adequately explain mtDNA sequence evolution ${ }^{4,5}$. This suggests that factors beyond those accounted for by the models are acting on mtDNA sequences. Incorporating these additional influences into our models will enhance our ability to correctly recover phylogenies by improving the correspondence between the model of evolution and actual evolutionary processes. Here

\footnotetext{
1. Avise, J. C. Molecular Markers, Natural History, and Evolution (Chapman and Hall, New York, 1994)

2. Sober, E. Reconstructing the Past: Parsimony, Evolution, and Inference. (MIT, Cambridge, Massachusetts, 1988). Goldman, N. Syst. Zool. 39, 345-361 (1990).

3. Goldman, N. Syst. Zool. 39, 345-361 (1990).
4. Fitch, W. M. in Evolutionary Processes and Theory (eds Karlin S.\& Nevo E. ) 315-328 (Academic, Orlando, Florida,1986).

5. Shoemaker, J. S. \& Fitch, W. M. Molec. Biol. Evol. 6 , 270-289 (1989).

6. Palumbi S. R. J. molec. Evol. 29, 180-187 (1989)

7. D. M. Irwin, T. D. Kocher \& Wilson A. C. J. molec. Evol. 32, 128-144 (1991)

8. Howell, N. J. molec. Evol. 29, 157-169 (1989).

9. Fearnley, I. M. \& Walker J. E. Biochim. biophys. Acta 1140, 105-134 (1992).

10. Walker, J. E. Q. Rev. Biophys. 25, 253-324 (1992).
}

we describe the mechanistic basis of a constraint acting on mtDNA sequences that represents one such influence.

It is well known that sites within DNA sequences differ in their relative freedom to vary ${ }^{6}$. In protein-encoding genes, third positions of codons typically vary more than first positions which, in turn, vary more than second positions, owing primarily to the differential degeneracy of the genetic code at these positions. It is often assumed that more rapidly evolving sites are more likely to result in chance matches (homoplasy) than are more slowly evolving sites when distant phylogenetic comparisons are made ${ }^{7}$. This may not necessarily be the case. If the 'character state space' (the number of possible states a site can exhibit) of a slowly evolving site is highly constrained, it could retain less phylogenetic information than a more rapidly evolving site for which more character states are available, because the probability that multiple substitutions will result in chance matches (homoplasy) across taxa increases as character-state space becomes more tightly constrained.

Constraints on character state space in DNA sequences are often reflected as deviations from a 1:1:1:1 ratio of the four bases $A, G, C$ and $T$. This condition is termed base compositional bias. We have investigated compositional bias at all three codon positions for the 13 proteinencoding genes in each of 12 taxa (see figure caption). There does not seem to be a 